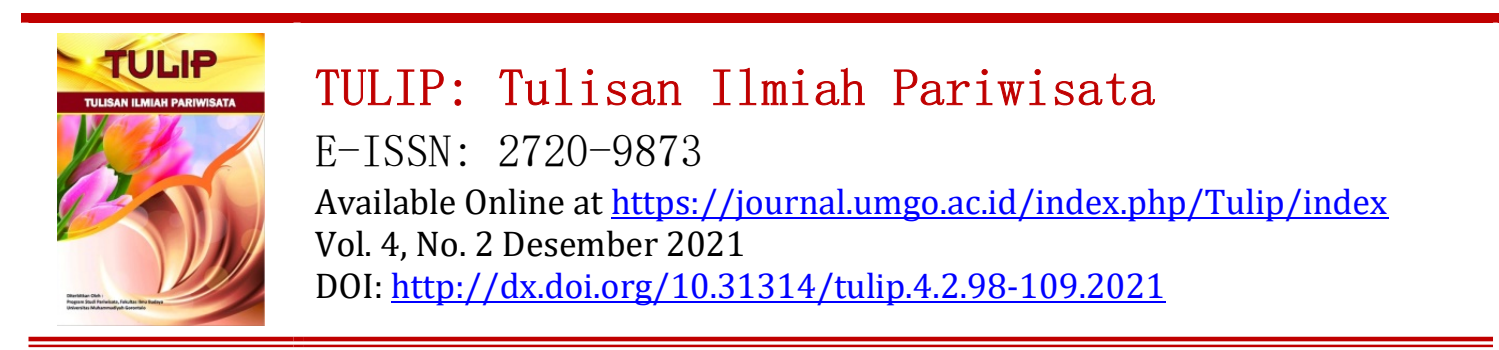

\title{
PERAN EKSPEKTASI KINERJA DAN EKSPEKTASI USAHA PENGGUNAAN TEKNOLOGI DALAM MEMEDIASI PENGARUH WORK FROM HOME TERHADAP KINERJA KARYAWAN ARCHIPELAGO INTERNATIONAL BALI
}

\author{
Eko Moh. Romi Kurniawan', Irene Hanna H. Sihombing', Nyoman Gde Dewa Rucika ${ }^{3}$ \\ 1,2,. Magister Terapan Pariwisata, Politeknik Pariwisata Bali, Indonesia \\ 3, Administrasi Perhotelan, Politeknik Pariwisata Bali, Indonesia \\ Email; Eko.k@archipelagointernational.com irenesihombing@ppb.ac.id dewarucika@gmail.com
}

\begin{tabular}{ll}
\hline \hline Info Artikel & Abstract: \\
Diterima: 20- & The purpose of this study was to determine the application of the unified theory \\
11-2021 & work from home on the performance of Archipelago Office Bali employees. Data \\
& were collected using a questionnaire with employees of the Bali Archipelago \\
Disetujui: 02- & office as respondents, totaling 45 respondents. Hypothesis testing using \\
$12-2021$ & structural equation model (SEM) analysis with the help of Smart PLS. This study \\
& concludes that working from home has a positive and significant effect on the \\
Publish: 04- & performance expectations of Archipelago Office Bali employees. Working from \\
$01-2022$ & expectations of Archipelago Office Bali employees. Working from home (Work \\
& from home) has a positive and significant impact on the business expectations \\
& of Archipelago Office Bali employees. Performance expectations have a positive \\
& and significant effect on the performance of Archipelago Office Bali employees. \\
& business expectations have a positive and significant effect on the performance \\
& of Archipelago Office Bali employees. Performance expectancy and effort \\
& expectancy are positively and significantly able to mediate the effect of work \\
& from home on employee performance, which means that if Archipelago \\
& International Indonesia Office Bali employees are able to facilitate good Work \\
& From Home for their employees, they will be able to form positive Performance \\
& expectancy for employees and this will be able to improve employee \\
& performance.
\end{tabular}

Keywords: UTAUT, WFH, Performance, Archipelago International Indonesia

\begin{abstract}
Abstrak:
Tujuan penelitian ini adalah mengetahui penerapan model unified theory of acceptance and use of technology (UTAUT) dalam memediasi pengaruh work from home terhadap kinerja karyawan Archipelago Office Bali. Pengambilan data dilakukan menggunakan kuesioner dengan karyawan Archipelago office Bali sebagai responden, berjumlah 45 responden. Pengujian hipotesis menggunakan analisis structural equation model (SEM) dengan bantuan Smart PLS. Penelitian ini menyimpulkan bahwa Bekerja dari rumah (Work from home) berpengaruh positif dan signifikan terhadap ekspektasi kinerja karyawan Archipelago Office Bali. Bekerja dari rumah (Work from home) berpengaruh positif dan signifikan terhadap ekspektasi usaha karyawan Archipelago Office Bali. Bekerja dari rumah (Work from home) berpengaruh
\end{abstract}


positif dan signifikan terhadap ekspektasi usaha karyawan Archipelago Office Bali. Ekspektasi kinerja berpengaruh positif dan signifikan terhadap kinerja karyawan Archipelago Office Bali. Ekspektasi usaha berpengaruh positif dan signifikan terhadap kinerja karyawan Archipelago Office Bali. performance expectancy dan effort expectancy secara positif dan signifikan mampu memediasi pengaruh work from home terhadap kinerja karyawan yang artinya apabila karyawan Archipelago International Indonesia Office Bali mampu memfasilitasi Work From Home yang baik bagi karyawannya, maka akan dapat membentuk Performance expectancy yang positif bagi karyawan dan hal tersebut akan mampu meningkatkan kinerja karyawan.

Kata Kunci: UTAUT, WFH, Kinerja, Archipelago International Indonesia

\section{PENDAHULUAN}

Fenomena pariwisata yang terjadi di dunia saat ini menunjukkan kecenderungan penurunan jumlah kunjungan wisatawan akibat wabah corona atau yang dikenal dengan sebutan Covid-19. Terbukti wisatawan mancanegara yang datang ke Bali pada tahun 2018-2020 mengalami fluktuasi setiap bulannya, namun dari akhir bulan Desember 2019 jumlah wisatawan mancanegara yang datang ke Provinsi Bali mencapai 6.275 .210 orang, kemudian terus mengalami penurunan yang signifikan pada tahun 2020 yang mencapai 1.069 .473 orang, lalu pada Januari 2021 menurun jumlahnya menjadi 10 orang wisatawan, dan menurun kembali hingga bulan Juni 2021 mencapai 1 orang wisatawan. Penurunan jumlah kunjungan wisatawan ke Bali tentunya sangat berdampak pada sektor perhotelan, khususnya pada industri hotel di Bali.

Hal ini diperkuat dengan data tingkat hunian Kamar Hotel di Bali yang mengalami penurunan signifikan selama wabah Covid19 melanda dunia. Hal ini menyebabkan tingkat hunian Kamar Hotel Berbintang menurun drastis hingga sebagian Hotel di
Bali memutuskan untuk menutup Hotel sementara dan banyak terjadi PHK pada karyawan hotel, sehingga jumlah tenaga kerja yang menganggur mengalami peningkatan di tahun 2019 dan 2020.

Berdasarkan instruksi Presiden Joko Widodo di Istana Bogor pada Minggu, (15/3), maka Kementerian Pendayagunaan Aparatur Negara dan Reformasi Birokrasi (PAN-RB) menyampaikan kebijakan nasional tentang penyesuaian sistem kerja Aparatur Sipil Negara selama merebaknya kasus Covid-19 sebagai Pedoman bagi Instansi Pemerintah.

Pelaksanaan sistem kerja dengan cara WFH yang dilakukan perusahaan di masa pandemi ini memang menjadi salah satu tantangan perusahaan dalam masalah kinerja karyawan. Work from home dalam prosesnya, terkadang membawa keuntungan dan kerugian bagi karyawan. Berdasarkan riset Microsoft dan TechRepublic Premium, perusahaan maupun karyawan seringkali lupa waktu karena terbiasa bekerja di rumah. Kedua, mewaspadai perkembangan karier karyawan selama WFH. Perusahaan perlu mengkaji kembali cara mengukur 
kinerja pegawai, meskipun dari jarak jauh.

Berdasarkan riset tersebut, pekerja dengan kepribadian tertutup atau introvert biasanya bekerja lebih baik di rumah. Tetapi, pekerja ekstrovert akan kesulitan mencapai kinerja maksimal saat WFH. Ketiga, perusahaan perlu menerapkan fleksibilitas dan empati. Riset menunjukkan, hampir setengah atau $47 \%$ orang yang bekerja dari rumah melaporkan gangguan teknis pekerjaan. Keempat, perusahaan perlu memberikan pelatihan dan kesiapan teknologi, sebab teknologi menjadi kebutuhan pokok bagi karyawan selama bekerja dari rumah. Kondisi tersebut menyebabkan pelatihan harus terus dilakukan untuk meningkatkan efektivitas kerja. terakhir, perusahaan perlu memasukkan unsur sosial. Kondisi tersebut disebabkan organisasi juga perlu berfokus pada kebijakan dan budaya perusahaan dibandingkan hanya mengandalkan penggunaan teknologi (Burhan dan Setyowati, 2020).

Bekerja secara online membuat karyawan juga mudah merasa lelah yang disebabkan menghadap laptop atau handphone secara terus menenrus yang mengakibatkan mudahnya terjadi kelelahan. Dengan adanya penurunan kinerja karyawan ini produktivitas dari perusahaan juga ikut menurun sehingga koefisien suatu perusahaan juga ikut menurun. Penurunan produktivitas perusahaan juga bisa menyebabkan kegiatan perusahaan tidak berjalan secara optimal, sehingga kualitas kerja yang menjadi keunggulan suatu perusahaan tidak berjalan optimal.

Salah satu perusahaan yang mengalami penurunan kinerja semenjak diterapkannya work from home adalah Archipelago Office Bali.

Gambar 1: Tingkat Produktivitas Kerja Karyawan Tahun 2019-2020

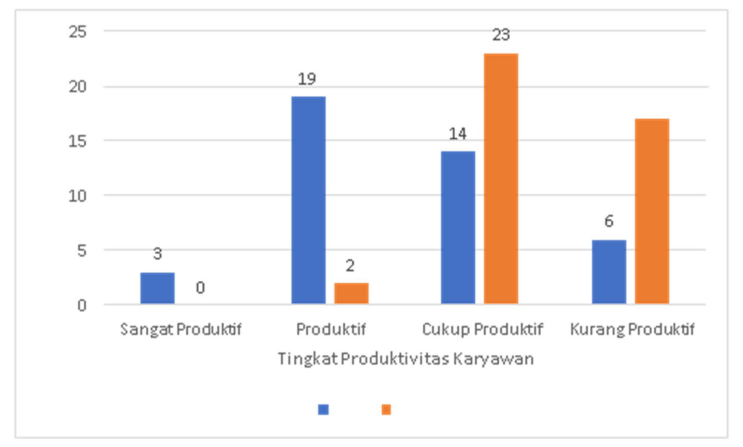

Sumber: HRD Archipelago Office Bali, 2021

Gambar tersebut menunjukkan bahwa pada tahun 2019 yakni sebelum adanya pandemi Covid-19 yakni work from office masih terdapat 3 orang karyawan yang sangat produktif dan 19 orang karyawan yang produktif, namun pada tahun 2020 saat karyawan mengalami work from home, jumlahnya mengalami penurunan yang signifikan menjadi 0 karyawan yang sangat produktif dan 2 karyawan saja yang produktif. Selanjutnya bila ditinjau dari jumlah karyawan yang cukup produktif di tahun 2019 mencapai 14 orang dan jumlah karyawan yang kurang produktif sebanyak 6 orang, lalu mengalami peninkatan karyawan yang kurang produktif di tahun 2020 yakni mencapai 17 orang. 
Kondisi yang menuntut karyawan bekerja dirumah tentunya sangat membutuhkan teknologi informasi dalam menunjang pekerjaan secara online tersebut. Seiring dengan perkembangan dan peningkatan kebutuhan untuk tercapainya kinerja organisasi yang ideal, perusahaan berlomba-lomba untuk menciptakan strategi inovasi yang handal. Komputerisasi merupakan salah satu strategi bagi perusahaan yang dapat meningkatkan produktivitas dan kinerja perusahaan melalui penghematan waktu, tenaga dan biaya dalam jangka panjang. Archipelago Internasional mengembangkan Microsite yang di pakai sebagai Communication Platform yang bisa di akses melalui mini website yang juga di gunakan untuk menampilkan semua informasi mengenai fasiltas hotel dan seluruh paket serta promo seperti paket ulang tahun, paket meeting, paket wedding atau pun promo dari food and beverage.

Tidak itu saja pada fasilitas Microsite tersebut juga sudah bisa melakukan booking dan akan diarahkan langsung ke sistem hotel dan dilengkapi oleh sistem payment gateway yang aman sebagai metode pembayaran melalui kartu kredit atau kartu debit. Penggunaan Internet Of Things (IoT) sebagai teknologi penunjang didalam layanan hotel saat ini menyediakan layanan TV Service, Google Assistant, Light \& AC Control, Routine Task, dan banyak lagi yang masih akan terus di kembangkan. Inovasi selanjutnya adalah
Self Check-ln sebagai sarana yang mendukung pemerintah dalam menerapkan protokol kesehatan, dengan layanan terbaru yakni melalui penggunaan Self Check-ln. Teknologi Self Check-ln yang diterapkan akan sangat efektif untuk memperkecil interaksi tamu dan staff hotel ketika ingin melakukan proses check-in.

Perusahaan pada masa mendatang dituntut untuk menciptakan keunggulan kompetitif yang dapat membawa perusahaan untuk memenangkan persaingan dan menciptakan keberhasilan perusahaan dalam jangka panjang. Kelangsungan hidup perusahaan sangat di tentukan oleh kemampuannya untuk bersaing di pasar.

Penelitian ini menggunakan dua variabel dari teori UTAUT yakni eskpetasi usaha dan ekpektaksi kinerja. Variabel work from home dalam penelitian ini akan diuji pengaruhnya terhadap ekspektasi usaha dan ekspektasi kinerja karyawan. Hal ini disebabkan karena dengan bekerja dari rumah, pegawai tentu akan merasakan kebebasan dalam menyelesaikan pekerjaan dikarenakan tidak ada pengawasan langsung dari atasan seperti saat mereka bekerja di kantor.

Sistem kerja work from home dapat memberikan karyawan kebebasan dalam mengatur waktu kerja dan tempat kerjanya. Karyawan tidak harus mengikuti aturan dimulai dan berakhirnya jam kerja seperti yang biasanya diberlakukan di kantor, sehingga hal tersebut membentuk ekspektasi 
usaha dan ekspektasi kinerja yang tinggi. Selain itu, tujuan digunakannya teori UTAUT adalah untuk membantu organisasi agar dapat memahami bagaimana karyawan bereaksi terhadap pengenalan teknologi baru dalam bekerja. Mengacu pada latar belakang masalah tersebut maka penelitian ini dilakukan dengan judul "Penerapan Model Unified Theory of Acceptance and Use of Technology (Utaut) dalam Memediasi Pengaruh Work from home Terhadap Kinerja Karyawan Archipelago Office Bali".

\section{METODE PENELITIAN}

Desain penelitian adalah suatu desain kerja terstruktur mengenai hubunganhubungan antar variabel yang disusun sedemikian rupa sehinga hasil penelitian mampu menjawab setiap pertanyaan yang diajukan. Penelitian ini menggunakan jenis data kuantitatif dan berbentuk penelitian asosiatif kausalitas. Penelitian ini dilakukan untuk mengetahui pengaruh work from home terhadap kinerja karyawan yang dimediasi oleh ekspektasi usaha dan ekspektasi kinerja karyawan Archipelago Office Bali.

Teknik pengumpulan data dalam penelitian ini menggunakan alat bantu kuesioner, dimana pertanyaan dalam kuisioner ini dirubah dalam bentuk pernyataan, sehingga tidak menimbulkan makna ambigu. Responden akan memilih salah satu jawaban yang telah disediakan, dengan alternatif jawaban terdiri dari interval bernilai 1 - 5. Hasil dan interpretasi pembahasannya akan disimpulkan dan selanjutnya akan diberikan saran penelitian. Terdapat dua jenis variabel penelitian yakni: variabel eksogen (work from home, effort expectancy, dan performance expectancy), serta variabel endogen (kinerja karyawan).

Penelitian ini dilakukan pada Archipelago International Indonesia Office Baliyang telah menerapkan sistem informasi akuntansi untuk mengolah data keuangannya.

Populasi penelitian ini adalah seluruh karyawan Archipelago International Indoneisa Office Bali yang berjumlah 45 orang. Seluruh divisi dalam penelitian ini diteliti karena memperoleh impact yang sama dalam penerapan UTAUT. Teknik penentuan sampel dalam penelitian ini adalah metode sensus.

Hasil penelitian yang valid dan reliabel menggunakan instrumen yang valid dan reliabel dengan pengujian instrument meliputi uji validitas dan reliabilitas. Teknik analisis data menggunakan uji statistik deskriptif dan analisis inferensial.

\section{HASIL DAN PEMBAHASAN}

Archipelago International adalah perusahaan manajemen hotel terdepan di Indonesia. Pada tahun 1997, Charles Brookfield selaku pendiri dari Archipelago International memulai usahanya dengan visi untuk membawa perubahan di industri perhotelan. Dalam 20 tahun terakhir, 
Archipelago mengubah visi tersebut menjadi kenyataan, dimana mereka menjadi pionir konsep kondotel pertama, memprakarsai "ledakan" hotel budget, menggunakan cloud computing, dan masuk ke bidang eCommerce di Indonesia sebelum hal- hal tersebut menjadi konsep yang umum. Dimulai hanya dengan 3 hotel, ekspansi Archipelago berkembang secara pesat dan belum pernah terjadi sebelumnya, dengan dibukanya 1 hotel setiap 2 minggu selama bertahuntahun hingga hari ini, dimana mereka kini merupakan salah satu dari 100 jaringan hotel terbaik di dunia, dengan portofolio hingga 137 hotel yang terbagi dalam tujuh brand yaitu: favehotel, NEO, Quest, Harper, Aston, Alana and Kamuela.

\section{Pengaruh Work From Home Terhadap Performance expectancy.}

Work from home adalah salah satu istilah bekerja dari jarak jauh (remote working), lebih tepatnya melakukan pekerjaan yang biasa dilakukan di kantor dari rumah. Jadi pekerja tidak perlu datang ke kantor tatap muka dengan para pekerja lainnya (Ashal, 2020). Berdasarkan hasil pengujian pada hipotesis, ditemukan pengaruh yang positif antara variabel Work From Home terhadap Performance expectancy yang artinya $\mathrm{H} 1$ diterima, berarti bahwa semakin tinggi atau semakin efektif dan efisien penerapan Work From Home yang diterima karyawan maka ekspektasi kinerja karyawan Archipelago Office Bali akan semakin meningkat.
Hasil penelitian ini didukung oleh penelitian yang dilakukan oleh Kelvyn dkk., (2021) yang menyatakan bahwa ada pengaruh yang signifikan work from home terhadap ekspektasi kinerja karyawan. Hasil penelitian serupa oleh Lisanti (2014) menyatakan bahwa efektivitas work from home berpengaruh signifikan terhadap ekspektasi kinerja karyawan. Hal ini disebabkan karena banyak keuntungan yang didapat dari implementasi bekerja dari rumah di antaranya adalah menawarkan fleksibilitas sehingga meningkatkan keseimbangan kehidupan dengan pekerjaan seorang pegawai, sehingga dapat meningkatkan ekspektasi kinerja yang semakin baik. Penelitian serupa oleh Soelistyoningrum (2020), Hartono dan Rahadi (2021) dan Simarmata (2020) juga menyatakan bahwa work from home (WFH) atau bekerja di rumah memiliki pengaruh positif signifikan terhadap produktivitas kerja ataupun ekspektasi kinerja.

\section{Pengaruh Work From Home Terhadap Effort expectancy}

Ekspektasi Usaha (Effort Expectancy) Merupakan tingkat kemudahan terkait dengan penggunaan sistem yang akan dapat mengurangi upaya (tenaga dan waktu) individu dalam melakukan pekerjaannya. Dengan menggunakan suatu sistem, pekerjaan dapat dilakukan secara lebih cepat. Keuntungan ini akan mempengaruhi seseorang dalam menyelesaikan setiap pekerjaannya. 
Faktor yang sering menjadi pertimbangan utama adalah faktor kemudahan dalam menyelesaiakan perkerjaan mereka. Hasil pengujian menemukan pengaruh positif dari variabel Work From Home terhadap effort expectancy yang artinya $\mathrm{H} 2$ diterima, berarti bahwa semakin tinggi atau semakin efektif dan efisien penerapan Work From Home yang diterima karyawan maka ekspektasi usaha karyawan Archipelago Office Bali akan semakin meningkat. Hasil penelitian ini sesuai dengan penelitian Marifah (2021) yang menyatakan terdapat berbagai keuntungan ataupun dampak positif dari sistem kerja dari rumah (work from home) seperti Fleksibilitas, Menghemat Waktu, adanya Waktu yang Berkualitas dan Kenyamanan, sehingga hal tersebut diharapkan dapat meningkatkan ekspektasi usaha yang lebih baik bagi karyawan dalam bekerja dan menggunakan teknologi informasi saat bekerja. Penelitian yang dilakukan Sakitri (2021) juga mengungkap bahwa work from home memberikan dampak positif dalam sejumlah aspek, seperti work life balance dan produktivitas, yang mengindikasikan bahwa karyawan memiliki ekspektasi usaha yang semakin tinggi dengan adanya work from home.

\section{Pengaruh Work From Home Terhadap}

\section{Kinerja karyawan}

Kinerja karyawan erat hubungannya dengan rasa mencintai pekerjaan tersebut, dimana karyawan yang bahagia tentu cenderung akan bekerja lebih produktif. Selain itu dengan bekerja dirumah yang merupakan lingkungan kerja yang nyaman bagi karyawan dapat menyebabkan fokus karyawan terhadap pekerjaan meningkat, dan kondisi ini menyebabkan tingkat produktivitas kerja karyawan meningkat sehingga target organisasi bisa dicapai (Tuwinanto dan Rahadi, 2020). Kinerja karyawan adalah hal yang penting untuk diperhatikan organisasi, karena dapat mempengaruhi tercapainya tujuan dan kemajuan organisasi dalam suatu persaingan global yang sering berubah. Berhasil tidaknya kinerja yang dicapai organisasi tersebut di pengaruhi kinerja karyawan secara individual maupun kelompok (Soelistyoningrum, 2020).

Berdasarkan hasil pengujian pada hipotesis, ditemukan pengaruh yang positif antara variabel Work From Home terhadap kinerja karyawan yang artinya H3 diterima, berarti bahwa semakin tinggi atau semakin efektif dan efisien penerapan Work From Home yang diterima karyawan maka kinerja karyawan Archipelago Office Bali akan semakin meningkat. Hasil penelitian ini didukung oleh penelitian yang dilakukan oleh Hartono dan Rahadi (2021) yang menyatakan bahwa kinerja karyawan yang dipekerjakan di rumah pada masa pandemi ini mempengaruhi kinerja kerjanya secara signifikan. Penelitian serupa oleh Kelvyn dkk. (2021), Ashal (2020), Soelistyoningrum (2020) Rahmah (2016) juga menyatakan ada 
pengaruh yang signifikan work from home terhadap kinerja karyawan.

\section{Pengaruh Performance expectancy} Terhadap Kinerja karyawan

Ekspektasi kinerja (performance expectancy) adalah sejauh mana seorang individu percaya bahwa menggunakan sistem akan membantu dia untuk mencapai keuntungan dalam pekerjaan atau kegiatan tertentu (Mahande dan Jasruddin, 2018). Berdasarkan hasil pengujian pada hipotesis, ditemukan pengaruh yang positif antara variabel Performance expectancy terhadap kinerja karyawan yang artinya H4 diterima, berarti bahwa semakin tinggi ekspektasi kinerja karyawan maka kinerja yang akan dicapai karyawan akan semakin meningkat. Hasil penelitian ini didukung oleh penelitian yang dilakukan Mahande dan Jasruddin (2018) mengungkapkan bahwa Performance expectancy adalah sejauh mana seorang individu percaya bahwa menggunakan sistem akan membantu dia untuk mencapai keuntungan dalam pekerjaan atau kegiatan tertentu agar dapat mencapai kinerja yang optimal.

Ekpektasi kerja yang ditunjukkan oleh rasa kepuasan kerja karyawan memiliki pengaruh positif signifikan terhadap kinerja karyawan. Hasil serupa juga diperoleh oleh Ayaz and Yanartas (2020) dan Setiadjie dan Widodo (2017) yang menyatakan bahwa konstruk ekspektasi kinerja merupakan prediktor yang kuat dari kinerja karyawan dalam pemanfaatan teknologi informasi secara sukarela maupun wajib. Dengan demikian ekspektasi kinerja berpengaruh positif dan signifikan terhadap kinerja karyawan.

\section{Pengaruh Effort expectancy Terhadap} Kinerja karyawan

Ekspektasi usaha (effort expectancy) adalah tingkat kemudahan terkait dengan penggunaan sistem/teknologi oleh pengguna. Kemudahan penggunaan teknologi informasi akan menimbulkan perasaan minat dalam diri seseorang bahwa sistem itu mempunyai kegunaan dan karenanya menimbulkan rasa yang nyaman bila bekerja dengan menggunakannya (Mahande dan Jasruddin, 2018). Berdasarkan hasil pengujian pada hipotesis, ditemukan pengaruh yang positif antara variabel effort expectancy terhadap kinerja karyawan yang artinya H5 diterima, berarti bahwa semakin tinggi ekspektasi usaha yang dimiliki karyawan, maka akan mampu meningkatkan kinerja karyawan Archipelago Office Bali.

Hasil penelitian ini didukung oleh penelitian yang dilakukan Omegawati (2015) yang menerangkan hasil pengujiannya bahwa effort expetancy terbukti memiliki pengaruh positif dan signifikan terhadap kinerja karyawan. Penelitian serupa oleh Sedana dan Wijaya (2012), Sancaka dan Subagio (2014), Omegawati (2015) serta Sisnuhadi (2016) yang menyatakan bahwa effort expectancy tingkat kemudahan penggunaan sistem dapat mengurangi upaya 
(tenaga dan waktu) individu dalam melakukan perkerjaan, sehingga dapat mencapai kinerja yang optimal.

\section{Peran Performance expectancy} Memediasi Pengaruh Work From Home Terhadap Kinerja karyawan

Berdasarkan hasil pengujian pada hipotesis, ditemukan bahwa performance expectancy secara positif dan signifikan mampu memediasi pengaruh work from home terhadap kinerja karyawan yang artinya H6 diterima. Hasil penelitian ini didukung oleh penelitian yang dilakukan oleh Kelvyn dkk (2021) dalam penelitiannya menyatakan bahwa Work from home berpengaruh secara tidak langsung Terhadap Kinerja Karyawan melalui variabel mediasi lingkungan kerja, kepuasan kerja dan motivasi kerja. Dengan adanya pelaksanaan Work From Home yang baik, maka akan meningkatkan Performance expectancy, hal ini karena berkaitan dengan persepsi atau pandangan dari karyawan itu sendiri mengenai nyamannya bekerja dari rumah, hal ini juga nantinya akan meningkatkan kinerja karyawan tersebut. Dengan demikian apabila karyawan Archipelago International Indonesia Office Bali mampu memfasilitasi Work From Home yang baik bagi karyawannya, maka akan dapat membentuk Performance expectancy yang positif bagi karyawan dan hal tersebut akan mampu meningkatkan kinerja karyawan Archipelago Office Bali.
Penelitian ini juga sejalan dengan penelitian yang dilakukan oleh Sancaka dan Subagio (2014) dalam penelitiannya menyatakan bahwa performance expectancy tingkat kemudahan penggunaan sistem dapat mengurangi upaya (tenaga dan waktu) individu dalam melakukan perkerjaan, sehingga dapat mencapai kinerja yang optimal. Penelitian serupa oleh Setiadjie dan Widodo (2017), Mahande dan Jasruddin (2018), serta Ayaz and Yanartas (2020) juga mengungkapkan bahwa Performance expectancy adalah sejauh mana seorang individu percaya bahwa menggunakan sistem akan membantu dia untuk mencapai keuntungan dalam pekerjaan atau kegiatan tertentu agar dapat mencapai kinerja yang optimal.

\section{Peran Effort expectancy Memediasi} Pengaruh Work From Home Terhadap Kinerja karyawan

Berdasarkan hasil pengujian pada hipotesis, ditemukan bahwa effort expectancy secara positif dan signifikan mampu memediasi pengaruh work from home terhadap kinerja karyawan yang artinya H7 diterima. Hasil penelitian ini didukung oleh penelitian yang dilakukan oleh Sedana dan Wijaya (2012) juga mendapatkan hasil penelitian bahwa effort expectancy memiliki korelasi positif dan signifikan terhadap kinerja karyawan. Kemudian, penelitian Ashal (2020) menyatakan ada pengaruh positif signifikan dari Work from home terhadap kinerja. 
Dengan adanya pelaksanaan Work From Home yang baik, maka akan meningkatkan Effort expectancy, hal ini karena berkaitan dengan persepsi atau pandangan dari karyawan itu sendiri mengenai nyamannya bekerja dari rumah, hal ini juga nantinya akan meningkatkan kinerja karyawan tersebut. Hal ini disebabkan karena bekerja dirumah yang merupakan lingkungan kerja yang nyaman bagi karyawan dapat menyebabkan fokus karyawan terhadap pekerjaan meningkat, dan kondisi ini mampu meningkatkan ekspektasi usaha seperti tingkat produktivitas kerja karyawan meningkat sehingga target organisasi bisa dicapai (Tuwinanto dan Rahadi, 2020).

Dengan demikian apabila karyawan Archipelago International Indonesia Office Bali mampu memfasilitasi Work From Home yang baik bagi karyawannya, maka akan dapat membentuk Effort expectancy yang positif bagi karyawan dan hal tersebut akan mampu meningkatkan kinerja karyawan Archipelago Office Bali.

Penelitian ini juga sejalan dengan penelitian yang dilakukan oleh Sancaka dan Subagio (2014) dalam penelitiannya menyatakan bahwa effort Expectancy Tingkat kemudahan penggunaan sistem dapat mengurangi upaya (tenaga dan waktu) individu dalam melakukan perkerjaan, sehingga dapat mencapai kinerja yang optimal. Penelitian serupa oleh Omegawati (2015) Mahande dan Jasruddin (2018), serta
Ayaz and Yanartas (2020) juga mengungkapkan bahwa Effort expectancy adalah sejauh mana seorang individu percaya bahwa menggunakan sistem akan membantu dia untuk mencapai keuntungan dalam pekerjaan atau kegiatan tertentu agar dapat mencapai kinerja yang optimal.

\section{KESIMPULAN}

1. H1 diterima, yakni Bekerja dari rumah (Work from home) berpengaruh positif dan signifikan terhadap ekspektasi kinerja karyawan Archipelago Office Bali. Hal ini berarti bahwa semakin tinggi atau semakin efektif dan efisien penerapan Work From Home yang diterima karyawan maka ekspektasi kinerja karyawan Archipelago Office Bali akan semakin meningkat.

2. H2 diterima, yakni Bekerja dari rumah (Work from home) berpengaruh positif dan signifikan terhadap ekspektasi usaha karyawan Archipelago Office Bali. Hal ini berarti bahwa semakin tinggi atau semakin efektif dan efisien penerapan Work From Home yang diterima karyawan maka ekspektasi usaha karyawan Archipelago Office Bali akan semakin meningkat.

3. H3 diterima, yakni Bekerja dari rumah (Work from home) berpengaruh positif dan signifikan terhadap ekspektasi usaha karyawan Archipelago Office Bali. Hal ini berarti bahwa semakin tinggi atau semakin efektif dan efisien penerapan 
Work From Home yang diterima karyawan maka kinerja karyawan Archipelago Office Bali akan semakin meningkat.

4. H4 diterima, yakni ekspektasi kinerja berpengaruh positif dan signifikan terhadap kinerja karyawan Archipelago Office Bali. Hal ini berarti bahwa semakin tinggi ekspektasi kinerja karyawan maka kinerja yang akan dicapai karyawan akan semakin meningkat.

5. H5 diterima, yakni ekspektasi usaha berpengaruh positif dan signifikan terhadap kinerja karyawan Archipelago Office Bali. Hal ini berarti bahwa semakin tinggi ekspektasi usaha yang dimiliki karyawan, maka akan mampu meningkatkan kinerja karyawan Archipelago Office Bali.

6. H6 diterima, yakni performance expectancy secara positif dan signifikan mampu memediasi pengaruh work from home terhadap kinerja karyawan yang artinya apabila karyawan Archipelago International Indonesia Office Bali mampu memfasilitasi Work From Home yang baik bagi karyawannya, maka akan dapat membentuk Performance expectancy yang positif bagi karyawan dan hal tersebut akan mampu meningkatkan kinerja karyawan.

7. H7 diterima, yakni effort expectancy secara positif dan signifikan mampu memediasi pengaruh work from home terhadap kinerja karyawan yang artinya apabila karyawan Archipelago

International Indonesia Office Bali mampu memfasilitasi Work From Home yang baik bagi karyawannya, maka akan dapat membentuk ekspektasi usaha yang tinggi bagi karyawan dan hal tersebut akan mampu meningkatkan kinerja karyawan.

\section{REFERENSI}

Ajzen, I., and Fishbein, M., 1975, Belief, Attitude, Intention, and Behavior: An Introduction to Theory and Research, 129-385, AddisonWesley, Reading, MA.

Burhan, A., dan D. Setyowati. 2020. Work from home Jadi Tren, Perusahaan Hadapi Lima Masalah. Diakses pada Tanggal 15 Juni 2021. https://katadata.co.id/desysetyow ati/digital/5f227ed32cbab/workfrom- home-jadi-tren-perusahaanhadapi-lima-masalah.

Davis, F. D. (1989). Perceived Usefulness, Perceived Ease of Use, and Acceptance of Information System Technology. MIS Quarterly Vol. 13 No. 3, 319-339.

Mubarok, M.Z., A. Kusyanti. Dan H. Aryadita. 2018. Faktor-Faktor Yang Memengaruhi Kepercayaan dan Resiko Pengguna dalam Bertransaksi Pada E-Commerce XYZ Menggunakan UTAUT (Unified Theory of Acceptance and Use of Technology). Jurnal Pengembangan Teknologi Informasi dan Ilmu Komputer Vol. 2, No. 9, September 2018, hlm. 3050-3057.

Omegawati, S. R. 2015. Pengaruh Performance Expectancy, Effort Expectancy dan Social Influence Terhadap Behavioral Intention 
Pada Ritel Online. Skripsi. Jurusan Manajemen Fakultas Bisnis Universitas Katolik Widya Mandala Surabaya.

Sibagariang, M. 2021. 5 Hal yang Mempengaruhi Kinerja Karyawan selama Work from home (WFH). Diakses pada Tanggal 15 Juni 2021. https://www.kompasiana.com/me gawaty24/6059cb868ede484f0915 dfb2/5-hal-yang-mempengaruhikinerja- karyawan-selama- workfrom- home-wfh.

Wilkinson, Joseph W. dan Michael J. Cerullo. (1997). Accounting Information System. 3rd Edition. (Diterjemahkan oleh Agus Maulana). Binarupa Aksara. Jakarta. 